\title{
2015 MID-ATLANTIC TELEHEALTH RESOURCE CENTER ANNUAL SUMMIT
}

\author{
KATHY HSU WIBBERLY, PHD
}

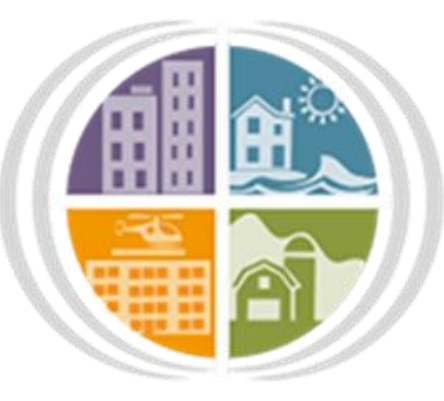

The Mid-Atlantic Resource Center (MATRC;

http://www.matrc.org/) advances the adoption and utilization of telehealth within the MATRC region and works collaboratively with the other federally funded Telehealth Resource Centers to accomplish the same nationally. MATRC offers technical assistance and other resources within the following mid-Atlantic states: Delaware, District of Columbia, Kentucky, Maryland, North Carolina, Pennsylvania, Virginia and West Virginia.

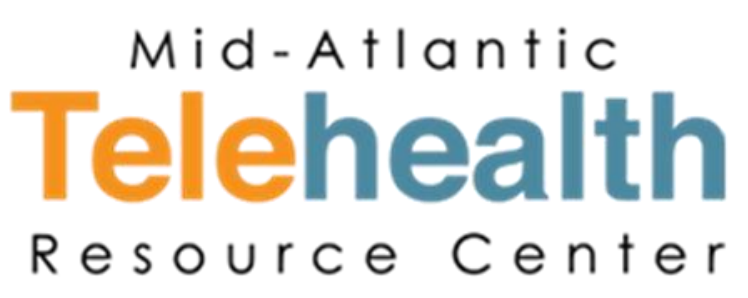

The 2015 MATRC Summit "Shaping the Future of Healthcare through Innovation and Technology" will be held March 29-March 31, 2015, at The Greenbrier, White Sulphur Springs, West Virginia. The Summit will explore how the partnership of human innovation and technological advancements is both shaping and transforming the future of healthcare.

For further information and registration, visit: http://matrc.org/summit/index.html 
